ductive cycle of a cell. The fourth chapter is an interesting historical account of the use (often misleading) of simulation experiments in biology. Its principal attraction is the delightful antiquated illustrations. The fifth and sixth chapters describe the simulation of cardiac and visual activities; in the latter, Frank Rosenblatt describes the performance of a new kind of perceptron. The seventh chapter is a valiant attempt to use Fourier transforms in analysing biological tracer data, but concludes with some rather discouraging comments. The most entertaining chapters are the third and eighth. Pattee's chapter reveals a clear logical mind looking at the origin of life from the point of view of a physicist, and the chapter by Louis Fein is a trenchant sermon on the need to clarify one's objectives before attempting to simulate any particular biological process. Fein distinguishes five kinds of simulation: investigation, education, emulation, imitation and stimulation. $\mathrm{He}$ suggests (convincingly enough) that many simulators do not know whether they are trying to discover something about a system, trying to explain it to somebody else, trying to copy it or trying to clarify their own ideas about it. All these goals are worthwhile, and they may even be combined together, but simulation experiments without a clear purpose are generally of very little use to anybody.

The book is a better 56s.-worth than most such collections.

H. C. Longuet-Higgins

\section{EMBRYOS IN THE LABORATORY}

\section{The Culture of Vertebrate Embryos}

By D. A. T. New. Pp. xi $+245+16$ plates. (London: Logos Press, Ltd., in association with Elek Books, Ltd., 1966. Distributed by Academic Press, New York and London.) 112s.

Embryologists have always had to face the problem of trying to persuade the animals they study to provide living embryos at a convenient time and place. Too many teachers of vertebrate embryology fail to face up to this challenge, and turn their practical classes solely into an attempt to reconstruct, from serial sections, the threedimensional changes undergone by the embryo through time. Students, by handling living embryonic material themselves, and by performing their own grafting or vital staining experiments, obtain a better insight into the dynamic processes of development than is given by a study of slides alone. Guided by practical experience gained in studies of the development of a great variety of animals Dr. New has selected for description in his book a rather small number of species, chosen as far as possible to represent the major vertebrate groups, all of which can be made to produce living embryos at a particular stage of development at a specified time in any period of the year. Dr. New, who has had considerable experience of culturing mouse, rat and chick embryos, has made a most useful compilation, from many not readily available sources, of information on obtaining living embryos from the selected species, and on the variety of methods by which they can be cultured. There is also a fully illustrated description of the embryonic stages of four of the species.

Fish are represented by the trout, the Japanese mekada (Oryzias, an aquarium fish), and the killifish (Fundulus). The stages of development of Fundulus are illustrated (unfortunately, Fundulus is not available in the United Kingdom, but its development is considered to be characteristic of teleosts).

Human pregnancy testing has brought deserved fame to the South African clawed toad, Xenopus, whose development is illustrated and which is considered in detail. Xenopus has the great advantage that it is easily maintained in the laboratory in a fertile condition throughout the year, and that breeding can be artificially induced in both male and female by injections of gonadotrophic hormone of either human or amphibian origin. Other amphibia are less convenient, often having a restricted breeding season, and requiring the injection of amphibian pituitaries into the female, and the sacrifice of the male to obtain spermatozoa for artificial fertilization. Breeding and rearing methods for the axolotl are also described.

Reptile embryology is represented by a description of the lizard Lacerta vivipara. Unfortunately, embryologists must rely on stalking pregnant female lizards (or finding eggs in other species) in the wild. By contrast, hen eggs are more tractable material and can be used for a wide variety of experimental purposes: methods are described for injecting substances into albumen, yolk, or blood vessels, for vital staining, for excision and for grafting on to the chorio-allantoic membrane. Alternatively, the blastoderm may be explanted from the yolk and grown on the vitelline membrane or on agar-albumen clots. An illustrated table of chick development is given. Mammals are represented by an account of methods of obtaining and culturing mouse and rabbit blastocysts, and Dr. New describes his own methods of obtaining and culturing post-implantation rat and mouse embryos.

There is a serious shortage of compact guides to growing embryos in the laboratory. Embryologists will find Dr. New's practical handbook an indispensable addition to Rugh's Experimental Embryology (1962) which, by comparison, is sketchy on mammals, ignores reptiles, and fails to emphasize the advantages of Xenopus. Rugh's massive compilation, however, remains essential: it contains, for example, illustrated developmental tables of seven amphibian and three fish species, together with detailed experimental procedures, particularly for the amphibia. The price of Dr. New's book seems high: Rugh contains well over twice as much material, and yet costs considerably less. Dr. New's book, in dealing "fairly fully with a few embryos rather than scrappily with many", has the advantage of compactness.

If the ideas in this book are put to good use in schools and universities, then practical classes in embryology will become much more exciting, and research workers will be given a stimulus to widen their field of activity.

J. R. Hinchliffe

\section{GRASSLAND RESEARCH}

\section{Nitrogen and Grassland}

Edited by P. F. J. van Burg and G. H. Arnold. (Proceedings of the First General Meeting of the European Grassland Federation, Wageningen, 1965.) Pp. 234. (Wageningen: Centre for Agricultural Publications and Documentation, 1966.) 25 D. fl.

The European Grassland Federation was constituted in 1963 to facilitate and maintain close contact between European grassland organizations, to promote the interchange of scientific and practical experiences between grassland experts, and to initiate symposia and other meetings between European grassland organizations. Membership is open to national or representative grassland organizations in Europe. Full details of the constitution are given in this, the proceedings of the first general meeting of the Federation, which was held at Wageningen, Netherlands, in July 1965, and was attended by more than 100 delegates from seventeen European countries.

The subject was the same as the title of this volume, Nitrogen and Grassland. Soil nitrogen, nitrogen and herbage yield, nitrogen and herbage quality, nitrogen and beef production, and nitrogen and the economy of dairy farming were considered in separate sessions. Inadequacy in the supply of nitrogen from the soil, from legumes and 